\title{
NMDA Receptor Blockade Maintains Correlated Motor Neuron Firing and Delays Synapse Competition at Developing Neuromuscular Junctions
}

\author{
Kirkwood E. Personius, ${ }^{1}$ James L. Karnes, ${ }^{2}$ and Sara D. Parker ${ }^{1}$ \\ ${ }^{1}$ Department of Rehabilitation Science, School of Public Health and Health Professions, University at Buffalo, Buffalo, New York 14214, and ${ }^{2}$ Division of \\ Rehabilitation Science, D’Youville College, Buffalo, New York 14201
}

\begin{abstract}
Mammalian neuromuscular synapses undergo an activity-dependent competitive transition from multiple to single innervation during postnatal life. The presence of temporally correlated motor neuron activity, which, in part, is controlled by gap junctional coupling within the spinal cord, appears to modulate synapse elimination. Postnatal injection of dizocilpine maleate (MK801), a specific NMDA antagonist, has been shown to maintain gap junctional coupling among motor neurons. Thus, we tested the hypothesis that MK801 would maintain correlated motor neuron activity and delay postnatal synapse elimination. Temporally correlated motor neuron activity, which is normally lost during the second postnatal week, was maintained and synaptic competition was delayed by several days in 2-week-old mice injected daily with MK801. MK801 appears to modulate motor neuron activity patterns through enhancing mRNA expression of multiple connexins within the spinal cord and delaying motor neuron growth. Our results suggest that MK801 injection preserves correlated neural activity via both synaptic mechanisms and maintenance of gap junctional coupling among neurons within the spinal cord, ultimately delaying synapse elimination.
\end{abstract}

Key words: motor neuron; gap junctions; activity; neuromuscular junction; competition; MK801

\section{Introduction}

Prenatal spontaneous neural activity affects motor neuron survival, motor neuron pathfinding, motor neuron axonal branching patterns, and number of neuromuscular junctions formed during development (Oppenheim et al., 2003; Hanson and Landmesser, 2004; Banks et al., 2005). GABAergic, glycinergic inputs, and gap junctional coupling among motor neurons appear to be the primary modulators of prenatal spontaneous activity patterns (Tresch and Kiehn, 2000; Oppenheim et al., 2003; Banks et al., 2005).

Neural activity also affects the later perinatal sorting and elimination of motor neuron inputs to skeletal muscle (Thompson, 1983; Sanes and Lichtman, 2001; Personius and Balice-Gordon, 2002; Personius et al., 2007). Multiple innervation is maintained when activity is eliminated, whereas enhanced activity accelerates the transition to single innervation (Thompson, 1983; Ridge and Betz, 1984; Callaway et al., 1987; Ribchester, 1993). The pattern of motor neuron activity also appears to modulate the outcome of competition (Personius and Balice-Gordon, 2002; Personius et al., 2007). Experimentally induced correlated neural activity

Received Nov. 26, 2007; revised July 15, 2008; accepted July 19, 2008.

We thank Drs. R. Balice-Gordon, G. Mentis, M. O'Donovan, and M. Slaughter for helpful discussions and Dr. Justin Spiegel for assistance with the motor unit analysis. We thank Dr. D. Paul for providing us with $\mathrm{C} \times 40$ and $\mathrm{C} 37 \mathrm{primary}$ antibodies. We are grateful to the University at Buffalo (K.E.P) and the D'Youville College Research Fund (J.L.K., K.E.P) for financial support.

Correspondence should be addressed to Dr. Kirkwood E. Personius, Department of Rehabilitation Science, Kimball Tower Room 515, 3435 Main Street, Buffalo, NY 14214-3079. E-mail: kep7@buffalo.edu.

DOI:10.1523/JNEUROSCI.5226-07.2008

Copyright $\odot 2008$ Society for Neuroscience $\quad$ 0270-6474/08/288983-10\$15.00/0 maintains multiple innervation (Busetto et al., 2000, 2003) but experimentally induced differential activity between synaptic inputs leads to the maintenance of the most active inputs, whereas the least active synapses are permanently deleted (Balice-Gordon and Lichtman, 1994; Buffelli et al., 2003). Motor neuron activity switches from a temporally correlated pattern to an uncorrelated pattern during the second week of normal postnatal development (Personius and Balice-Gordon, 2001; Buffelli et al., 2002). Together, these results suggest that the absolute amount of neural activity between the motor neurons innervating the same muscle fiber is a key determinant in the outcome of synapse elimination and that temporally correlated motor neuron activity may maintain multiple innervation, whereas the loss of correlated activity may trigger synaptic competition.

Gap junctions between motor neurons appear to play a key role in the developmental shift from correlated to uncorrelated activity. In situ hybridization shows that developing motor neuron express five gap junctions (Cx36, Cx37, Cx40, Cx43, and Cx45), but coupling among motor neurons rapidly disappears between the first and second postnatal week (Fulton et al., 1980; Walton and Navarrete, 1991; Chang et al., 1999). During this same time period, $\mathrm{Cx} 40$ and $\mathrm{Cx} 45$ mRNA expression in the spinal cord is reduced and neural activity changes from a temporally correlated to uncorrelated pattern (Personius and BaliceGordon, 2001; Buffelli et al., 2002). Finally, Cx40-null mice exhibit reduced electrical coupling among lumbar motor neurons, reduced temporally correlated motor neuron activity, and accelerated neuromuscular synapse elimination compared with wild- 
type littermates (Personius et al., 2007). Thus, gap junctional coupling among neurons with the spinal cord appears to modulate the extent of temporally correlated activity among motor neurons and, in turn, alters the time course of synaptic competition at neuromuscular junctions.

Mentis et al. (2002) has shown that gap junctional coupling among motor neurons is maintained during postnatal development when NMDA receptors are blocked with the noncompetitive antagonist dizocilpine maleate (MK801). In the present work, we test the hypothesis that MK801 injection would prolong the period of temporally correlated motor activity and delay postnatal synapse elimination.

\section{Materials and Methods}

Animals and pharmacological injections. All procedures were performed in strict compliance with the Institutional Animal Care and Use Committee of the University at Buffalo. Embryonic day 17 timed pregnant CD-1 mice were obtained from Charles River Laboratories, and each litter was culled to the size of 10-12 pups after birth. The day of birth was designated postnatal day $0(\mathrm{P} 0)$. Starting on $\mathrm{P} 2$, the pups received daily intraperitoneal injections of MK801 (1 mg/kg), p-chlorophenylalanine (PCPA) $(200 \mathrm{mg} / \mathrm{kg})$, or an equal volume of vehicle (saline) until the pups reached P7-P8 or P15-P16 when EMG recordings were performed. Daily doses of MK801, PCPA, or saline were given on the day of EMG recordings. MK801 is known to cross the blood-brain barrier and has been reported to reduce polysynaptic reflexes in vivo (Fenaux et al., 1991; Farkas and Ono, 1995), whereas PCPA has been shown to deplete serotonin (5-HT) in the CNS at this dose (Lauder et al., 2000). PCPA injection has been shown to slow maturation of repetitive motor neuron firing properties during later postnatal development, most likely through changes in intrinsic membrane properties (Pflieger et al., 2002). Thus, PCPA was used to determine the influence of intrinsic motor neuron properties on synapse elimination, whereas MK801 was used to determine the influence of gap junctional coupling. To assess the effect of PCPA and MK801 on overall development, weight gain, hair growth, and eye opening was monitored daily.

Immunohistochemistry. All animals were killed by intraperitoneal injection of Nembutal ( $100 \mathrm{mg} / \mathrm{kg}$ body weight) before harvesting of tissue. Whole mounts of the extensor digitorum longus (EDL) and soleus muscles were immunostained for motor axons, nerve terminals, and postsynaptic acetylcholine receptor (AChR) clusters to analyze the extent of fiber multiple innervation as described previously (Gonzalez et al., 1999; Personius and Balice-Gordon, 2001). Briefly, the primary antibodies mouse monoclonal anti-neurofilament SMI31 (Sternberger Monoclonals) and mouse monoclonal anti-SV2 (Developmental Studies Hybridoma Bank) and a fluorescently conjugated secondary antibody (AF488; Invitrogen) were used to label motor nerve terminals. Rhodamine-conjugated $\alpha$-bugarotoxin (Invitrogen) was to label acetylcholine receptors. Immunostained neuromuscular junctions were analyzed by conventional epifluorescence $(100 \times, 1.4$ numerical aperture, oil objective; Olympus BX51; Olympus America) or confocal microscopy (Zeiss LSM 510 Meta NLO; Carl Zeiss). The number of axons innervating individual AChR clusters was counted in $67 \pm 5.8$ (21-219) junctions from each of 5-10 muscles from each experimental group at P8-P9 and P15-P16.

To assess whether MK801 injection changed motor neuron morphology, lumbar spinal cords were removed and fixed overnight at $4{ }^{\circ} \mathrm{C}$ in $4 \%$ paraformaldehyde, rinsed in PBS, cryoprotected in $20 \%$ sucrose solution until spinal cords sank, mounted in molds containing OTC compound, and frozen in dye-ice-cooled acetone. Frozen tissue sections $(20 \mu \mathrm{m})$ were picked up on charged glass slides, rinsed with PBS, blocked with $1 \%$ BSA and $0.1 \%$ Triton X-100 in PBS, incubated with anti-ChAT derived in goat (Millipore Bioscience Research Reagents), and visualized by cyanine 5 mouse anti-goat (Jackson ImmunoResearch). Slides were examined by confocal microscopy. Motor neurons were identified on the basis of their large soma, anterior horn location, and ChAT labeling and were only evaluated if a nucleus was visible. Motor neuron soma cross-sectional area (CSA) was assessed using MetaMorph software (Molecular De- vices). Assessments of the percentage multiply innervated muscle fibers and motor neuron CSA were performed blind to experimental groups.

Quantitative PCR. To quantify whether connexin mRNA expression was changed by MK801 injection, total RNA was extracted from lumbar spinal cord using the SV Total RNA Isolation System (Promega). Total RNA $(1-5 \mu \mathrm{g})$ was reverse transcribed into first-strand cDNA in a $20 \mu \mathrm{l}$ reaction volume using oligo- $\mathrm{dT}_{12-18}$ primer (Invitrogen), four dinucleotide triphosphates (dNTPs) ( $5 \mathrm{~mm}$ each), $10 \times$ first-strand buffer, RNaseOUT Recombinant Ribonuclease Inhibitor, and StrataScript reverse transcriptase (Stratagene). The reaction conditions were $95^{\circ} \mathrm{C}$ for $4 \mathrm{~min}$, $94^{\circ} \mathrm{C}$ for $30 \mathrm{~s}, 60^{\circ} \mathrm{C}$ for $30 \mathrm{~s}, 72^{\circ} \mathrm{C}$ for $1 \mathrm{~min}$ for 40 cycles, followed by $72^{\circ} \mathrm{C}$ for $10 \mathrm{~min}$.

Real-time quantitative PCR (QPCR) (Mx4000 Multiplex System; Stratagene) was performed using the following forward and reverse primers: Cx37, TCCTCAAAGGCACCTCAGAGACAA and TGGTCATCACAAAGGTCCAGGTA; Cx40, ATTCGTCGTCGGCCATCATGCTTA and TTCCACTGAACTTGGTGGCTGGTA; Cx43, CGAGGGGAAGGAGTTTTC, and TGCAATGAAGCTGAACATGA; and Cx45, CAATCCAGGCCTACCATCACCAAA and ATGAGCCAACAGCATCCCTGAAGA. Briefly, gene expression was determined using $50 \mu \mathrm{l}$ reactions containing $1.5 \mathrm{MgCl}_{2}, 0.5 \mu \mathrm{M}$ for each primer, $200 \mu \mathrm{M}$ for each dNTP, PCR buffer, $0.5 \mu \mathrm{l}$ of SYBR Green II and ROX dyes, and $1 \mathrm{U}$ of MasterTaq DNA polymerase (Promega). The thermocycle for all connexins was $94^{\circ} \mathrm{C}$ for $4 \mathrm{~min}, 94^{\circ} \mathrm{C}$ for $30 \mathrm{~s}, 62^{\circ} \mathrm{C}$ for $30 \mathrm{~s}, 72^{\circ} \mathrm{C}$ for $1 \mathrm{~min}$ for 40 cycles. Each sample was run in duplicate, and each sample was run twice.

mRNA copy number was based on absolute quantification using an external calibration curve constructed from measurements of cloned PCR products. The PCR product of each gene was cloned into a pCR 2.1 TOPP vector and transformed into One Shot chemically competent Escherichia coli cells (Invitrogen). cDNA plasmids were extracted from the E. coli cells using a Wizard Plus DNA purification kit (Promega). The plasmid DNA was quantified by spectrophotometry and diluted to make standards. A standard curve was run concurrently with each set of unknowns. The initial copy number of amplicons was quantified during QPCR based on threshold cycle. Final mRNA value were expressed as copy number per microgram sample RNA (Gosselin et al., 2007).

Single motor unit EMG recordings. Methods to record single motor unit EMG signals from the soleus muscle have been described in detail previously (Personius and Balice-Gordon, 2001). P8-P9 and P14-P15 mice were anesthetized by intraperitoneal injection of $0.05-0.2 \mathrm{cc}$ mixture of $17.4 \mathrm{mg} / \mathrm{ml}$ ketamine and $2.6 \mathrm{mg} / \mathrm{ml}$ xylaxine along with $2.5 \mathrm{mg} / \mathrm{kg}$ Diazepam (Abbott Laboratories) to reduce stress. The soleus muscle was exposed via a small incision, and the mice were placed in a standing position with the hindlimbs and trunk restrained by soft dental wax. A single $75 \mu \mathrm{m}$ stainless steel microelectrode ( $1 \mathrm{M} \Omega$; FHC) was inserted into the soleus near the endplate band, and $125 \mu \mathrm{m}$ Teflon-coated platinum wire with beveled tip (A-M Systems) was threaded under the soleus muscle. The entire field was then bathed in mineral oil to reduce electrical crosstalk and potentially increase signal size. Recording began when spontaneous motor unit activity was observed as the animals recovers from anesthesia. Recordings were stable for up to $1 \mathrm{~h}$ as the animals spontaneously stood within the wax restraint. EMG signals are filtered (500 Hz high pass), amplified, and digitized through high-impedance preamplifiers and differential amplifiers (Tucker-Davis Technologies). Recording were not made from the EDL because the EDL is not tonically active in stance.

Analyses of single motor unit activity. Single motor units were discriminated off-line using Spike2 software (Cambridge Electronic Design), which used template matching to sort motor units based on the unique shape of their compound action potential. Generally, 8-10 single motor units could be discriminated from each muscle recording, but only three to six units exhibited sufficient activity across the entire recording period to be further analyzed. The accuracy of discrimination was verified by monitoring interspike interval and monitoring accuracy of template matching for every motor unit (Nordstrom et al., 1992; Personius and Balice-Gordon, 2001). Mean and median motor unit firing frequency were determined from interspike interval histograms (1000 60-ms bins spanning a $60 \mathrm{~s}$ period). Overall motor unit activity was determined by 
counting the number of spikes occurring during the entire recording period (spikes per second).

Cross-correlograms were generated with bin widths of $100 \mathrm{~ms}$ over a period of $\pm 25 \mathrm{~s}$ to investigate the presence of broad correlations (Meister et al., 1991; Torborg et al., 2005) and with bin widths of 2 or $10 \mathrm{~ms}$ over periods \pm 2.5 or \pm 0.25 s to investigate short-term correlations (Nordstrom et al., 1992). Normalized cumulative sum analyses were used to identify the position and duration of the cross-correlogram peak and the strength of correlation was determined using the index $k^{\prime}-1(100 \mathrm{~ms}$ bins, the ratio of the total number of extra counts within the peak region above that expected attributable to chance relative to the number expected attributable to chance alone) (Nordstrom et al., 1992). To examine the correlations at specific timescales, we determined a correlation index, as described by Wong et al. (1993), within time windows of 10, 20, 50 , and $100 \mathrm{~ms}$ and 1 and $10 \mathrm{~s}$. The correlation index (CI) was calculated as a ratio of the number of events from one unit that occurred within a $10-10,000 \mathrm{~ms}$ window of events from a second unit, divided by the number of events that would be expected if the two units were firing random to one another. An index of 1 indicates that the activity of the two units is independent, whereas an index $>1$ implies that the units are more likely to fire together within the specific time window than expected by chance (Personius and Balice-Gordon, 2001; Personius et al., 2007). Thus, the CI determines how more likely a pair of neurons fires together within a particular time window than by chance alone. Assessment of motor unit correlations were performed blind to experimental groups.

Statistical analysis. All values are reported as mean \pm SEM unless otherwise noted. When all three experimental groups (MK801, saline, and PCPA) were compared, a one-way ANOVA with Holm-Sidak post hoc test was used. If data were non-normal, a Kruskal-Wallis ANOVA was used. A Student's test or, if data were non-normal, a Mann-Whitney rank sum test was used for analyses across just two experimental groups. Significance was set at $p \leq 0.05$.

\section{Results \\ Pharmacological blockade of NMDA or 5-HT receptors did not affect general postnatal development}

Based on the results of Mentis et al. (2002), we intraperitoneally injected MK801, PCPA, or saline daily from P2 until P7-P8 or P15-P16. MK801 and PCPA injections did not affect overall development, because weight gain, hair growth, and eye opening was similar to the saline-injected pups. P7-P8 pups weighed $3.9 \pm 0.2,3.6 \pm 0.5$, and $4.2 \pm 0.3 \mathrm{~g}$ for saline, MK801, and PCPA, respectively $(p=0.374$, Kruskal-Wallis ANOVA; $n=7-22$ mice). P14-P15 mice weighed $8.8 \pm 0.2,7.8 \pm 0.3$, and $7.7 \pm$ $0.2 \mathrm{~g}$ for saline, MK801, and PCPA, respectively $(p=0.095$, Kruskal-Wallis ANOVA; $n=7-25$ mice). Hair growth was visible between $\mathrm{P} 4$ and $\mathrm{P} 5$, and eye opening occurred at approximately P14 for all experimental groups.

\section{Synapse elimination is delayed in both P7-P8 and P15-P16 animals injected with MK801 compared with PCPA or saline- injected controls}

Because MK801 had been shown to delay the developmental reduction of gap junction coupling, we hypothesized that MK801 injection would prolong correlated motor unit activity and delay synapse elimination. We hypothesized that PCPA injection would have a similar effect because of a delayed maturation of motor activity patterns, because PCPA has been shown to effect neonatal posture and prevent the maturation of repetitive firing patterns seen during later postnatal development (Pflieger et al., 2002). The time course of synapse elimination, however, was significantly delayed in the soleus and EDL muscles in only the MK801-injected group (Fig. 1). At P8-P9, $75 \pm 2 \%$ of muscle fibers were multiply innervated in the soleus muscles of MK801injected pups compared with $58 \pm 2$ and $50 \pm 5 \%$ of muscle fibers in saline- and PCPA-injected pups, respectively $(p=$ 0.001 , one-way ANOVA; $n=5-10$ pups for each experimental group). Similar results were seen in the EDL muscles from P7-P8 pups; $67 \pm 2 \%$ of muscle fibers were multiply innervated after MK801 injection compared with $53 \pm 2$ and $52 \pm 5 \%$ of muscle fibers in saline- and PCPA-injected pups, respectively ( $p=$ 0.005 , one-way ANOVA; $n=5-7$ pups). The percentage multiple innervation in the saline- and PCPA-injected groups are similar to previously reported values, because hindlimb muscles are generally $\sim 50 \%$ multiply innervated at this age. MK801 injection appears to delay synapse elimination at P7-P8 by $\sim 4 \mathrm{~d}$, because $\sim 75 \%$ of hindlimb muscle fibers are multiply innervated by P4-P5 during normal postnatal development (Lichtman and Colman, 2000; Personius and Balice-Gordon, 2001).

Synapse elimination remained delayed after MK801 injection in P14-P15 mice in both the soleus and EDL muscles (Fig. 1C,D). For the soleus, $10 \pm 2 \%$ of muscle fibers were multiply innervated in MK801-injected P14-P15 mice compared with $4 \pm 1$ and $5 \pm$ $1 \%$ of muscle fibers in saline- and PCPA-injected pups, respectively ( $p=0.02$, one-way ANOVA; $n=5-7$ pups). For the EDL, $10 \pm 1 \%$ of muscle fibers were multiply innervated in MK801injected P14-P15 mice compared with $1 \pm 1$ and $4 \pm 1 \%$ of muscle fibers in saline- and PCPA-injected pups, respectively ( $p=0.001$, one-way ANOVA; $n=5-7$ pups). MK801 injection appears to continue to delay synapse elimination by $\sim 4 \mathrm{~d}$ at P15-P16, because $\sim 10 \%$ of muscle fibers are multiply innervated at P11-P12 (Balice-Gordon and Lichtman, 1993; Personius and Balice-Gordon, 2001). Thus, MK801 injection significantly delays the time course of synapse elimination.

\section{Temporally correlated motor unit activity is increased in MK801 compared with PCPA-injected mice}

We hypothesized that MK801 injection would delay synapse elimination by prolonging the postnatal period of correlated motor unit activity. To investigate whether MK801 injection affected motor unit activity compared with PCPA or saline treatment, we performed EMG recordings in both P7-P8 $(n=3-5$ mice) and P15-P16 ( $n=4-5$ mice). Because MK801 reduces glutamatergic activity, the major excitatory neurotransmitter within the CNS, we expected that motor neuron activity may be decreased in MK801-injected pups compared with control. Figure 2 shows box plots of the motor unit firing frequencies in saline-, PCPA-, and MK801-injected mice at both experimental age groups. Median motor unit firing frequency was similar across experimental groups in P7-P8 pups $(1.8 \pm 0.6,1.6 \pm 0.9$, and $2.3 \pm 0.5 \mathrm{~Hz}$ for saline-, PCPA-, and MK801-injected pups, respectively). Median motor unit firing frequency, however, was increased in P15-P16 MK801-injected pups compared with saline controls ( $p=0.007$, ANOVA on rank with Dunn's post hoc test; $0.7 \pm 0.2,1.3 \pm 0.2$, and $4.8 \pm 1.3 \mathrm{~Hz}$ for saline-, PCPA-, and MK801-injected mice, respectively), possibly attributable to the more phasic pattern of motor unit activity in MK801-treated mice. Similar results were also seen when we compared the number of motor unit spikes within the entire recording session. These values were much lower than the median firing frequency because long periods of motor unit inactivity occur within each recording session. At $\mathrm{P} 7-\mathrm{P} 8$, the average number of spikes per second was $0.03 \pm 0.01$, $0.03 \pm 0.01$, and $0.04 \pm 0.004$ for saline-, PCPA-, and MK801injected pups, respectively. The average number of spikes per second was $0.09 \pm 0.04,0.12 \pm 0.04$, and $0.33 \pm 0.12$ for saline-, PCPA-, and MK801-injected pups at P15-P16, respectively. There was no difference in spikes per second between experimental groups at P7-P8 or P15-P16. Thus, MK801 injection did not 
reduce motor unit firing frequency but tended to increase firing frequency compared with saline- or PCPA-injected control animals.

As hypothesized, the strength of motor unit temporal correlation was increased in MK801 compared with saline- or PCPAinjected pups at both experimental ages. Figure $3 A$ shows sample raw EMG recordings from PCPA- and MK801-injected pups. Raw records were frequently more "bursty" in MK801-injected pups. Overlays of 20 discriminated motor units are shown in Figure $3 B$ to demonstrate the motor unit waveform shape and quality of spike discrimination. Cross-correlogram and normalized cumulative sum analysis were used to determine whether each motor unit pair showed temporally correlated motor activity. The presence of a sharp peak in the cross-correlogram indicated that the activity of the motor units was correlated, whereas the width of the peak represents the time course of correlation. An example of motor unit correlation from a P7-P8 MK801-injected pup is shown in Figure $3 C$. The time course of correlation was $\sim 1.4 \mathrm{~s}$, which closely matches the cross-correlogram peak duration (1.7 s) we found previously in CD-1 mice (Personius and Balice-Gordon, 2001). The width of the peak $(\sim 1 \mathrm{~s})$ was unaffected when the cross-correlogram was constructed using smaller bin widths (Fig. 3C, right). The index $k^{\prime}-1$ was used to assess the strength of temporal correlation between motor unit pairs (Nordstrom et al., 1992). The median index $k^{\prime}-1$ was significantly increased in MK801-injected compared with saline- or PCPA-injected controls ( $p \leq$ 0.001, ANOVA on ranks with Dunn's post hoc test) and was well above the values reported previously in mice of this age (Personius and Balice-Gordon, 2001). The mean index $k^{\prime}-1$ was $0.23 \pm 0.28,0.25 \pm$ 0.26 , and $4.1 \pm 0.79$ for saline-, PCPA-, and MK801-injected pups (Fig. $3 D)(n=8$, 10 , and 11 motor unit pairs, respectively). The CI was used to determine how likely a pair of neurons fire together within a particular time window than would be expect to occur by chance alone. Motor unit pairs from MK801-injected pups had significantly larger CI values for both 20 and $100 \mathrm{~ms}$ time windows than saline- or PCPA-injected controls (ANOVA on ranks with Dunn's post hoc test; $p=0.014$ and 0.005 for 20 and $100 \mathrm{~ms}$, respectively). The mean CI values calculated over $20 \mathrm{~ms}$ bins (short-term correlations) were 9.9 $\pm 6.6,2.5 \pm 2.3$, and $26.3 \pm 8.8$ for saline-, PCPA-, and MK801-injected pups, respectively (Fig. 3E). Mean CI values calculated over $100 \mathrm{~ms}$ bins (broad correlations) are similar to those using $20 \mathrm{~ms}$ bins, with values of $6.1 \pm 3.2,1.4 \pm 0.5$, and $23.0 \pm 6.0$ for saline-, PCPA-, and MK801-injected pups, respectively (Fig. $3 F$ ).

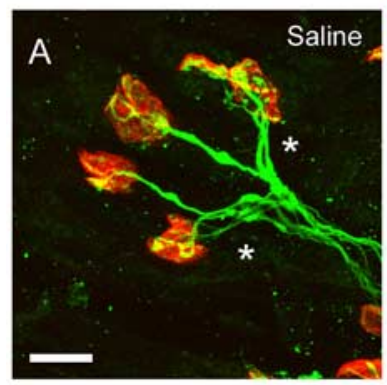

P7 - P8
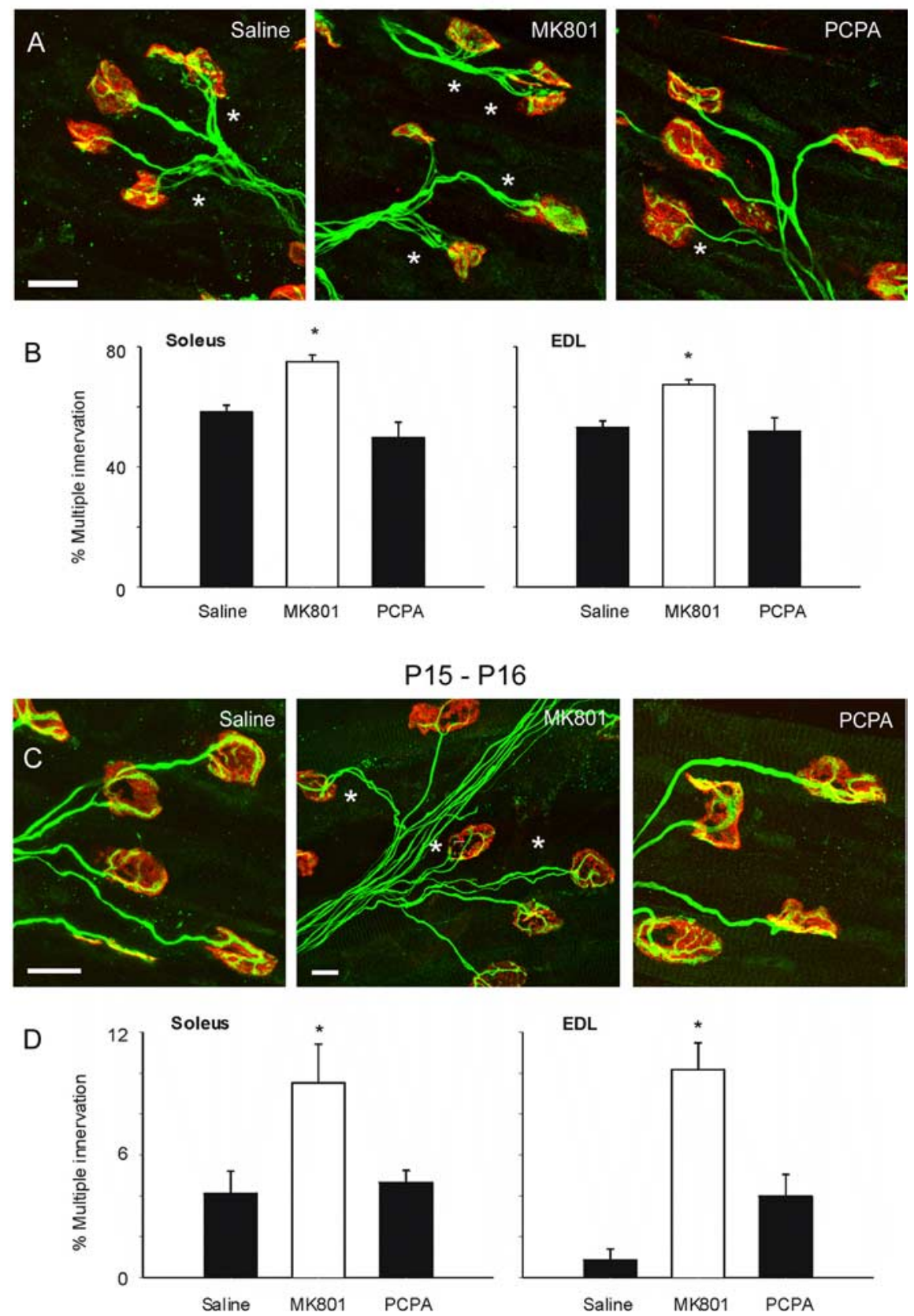

Figure 1. Synapse elimination is delayed at P7-P8 and P15-P16 after MK801 injection. $\boldsymbol{A}$, Confocal images of neuromuscular junctions from soleus of P7-P8 mice immunostained from presynaptic axons and nerve terminals (green) and postsynaptic AChRs (red). Asterisks mark multiply innervated junctions (scale bar, $40 \mu \mathrm{m}$ ). $\boldsymbol{B}$, The percentage of multiply innervated neuromuscular junctions was significantly greater in MK801-injected mice compared with saline- or PCPA-injected pups in both the soleus and EDL muscles ( ${ }^{*} p \leq 0.001$ and 0.005 , respectively, one-way ANOVA; $n=5-10$ animals). C, Synapse elimination is nearly complete by P15-P16 in saline- and PCPA-injected mice, but regions of multiple innervation are seen in MK801-injected mice. Asterisks mark multiply innervated junctions (scale bars, $40 \mu \mathrm{m}$ ). $\boldsymbol{D}$, The percentage of multiply innervated neuromuscular junctions remained significantly greater in MK801-injected mice compared with saline- or PCPA-injected animals in both the soleus and EDL muscles ( ${ }^{*} p=0.02$ and $\leq 0.001$, respectively, one-way ANOVA; $n=5-7$ animals).

Figure $4 A$ shows raw EMG recordings from PCPA- and MK801-injected P15-P16 pups. Raw records continued to be bursty in MK801-injected pups. The expanded trace demonstrates a number of spikes from different motor units within the activity burst. Bursts of activity were generally briefer $(<0.1 \mathrm{~s})$ in P15-P16 mice compared with P7-P8 pups ( $\sim 0.5 \mathrm{~s})$. Overlays of discriminated motor unit waveforms are shown in Figure $4 B$. Figure $4 C$ (middle and right) shows an example of motor unit 


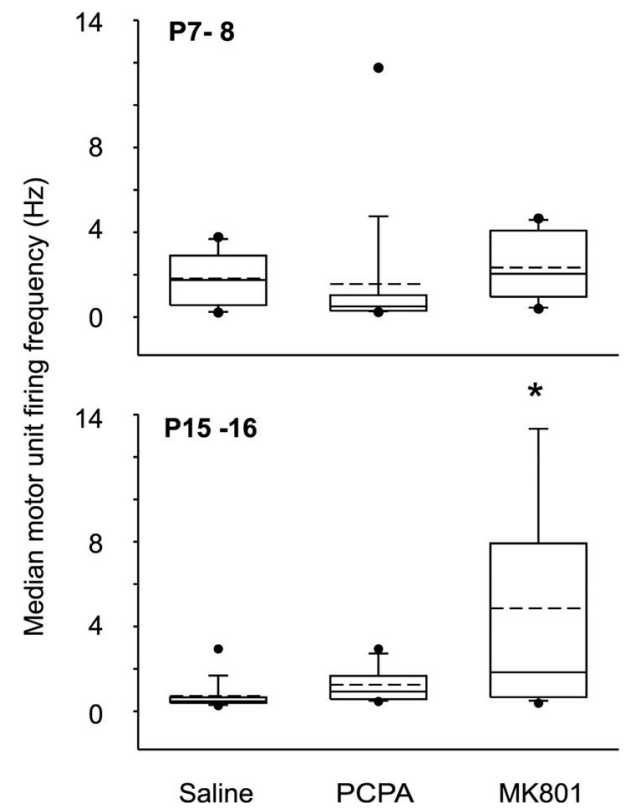

Figure 2. Median firing frequency is similar in the soleus muscle of saline-, PCPA-, and MK801-injected mice. Box plots of the median motor neuron firing frequency. The dashed line indicates the mean value, the box encompasses the 25 th to 75 th percentile, and the bars delineate the 10th to 90 th percentile. Filled circles indicate data points outside the 10th to 90 th percentiles. Firing frequency was similar between all experimental groups at P7-P8. A significant increase in firing frequency, however, was found between saline- and MK801-injected pups at P15-P16 (ANOVA on ranks with Dunn's post hoc test, $p=0.007 ; n=8-11$ motor unit pairs at P7-P8; $n=13-26$ motor unit pairs at P15-16).

correlation from a P15-P16 MK801-injected pup at two different timescales (constructed with 100 and 2 ms bins, respectively). The width of the cross-correlogram peak $(\sim 23 \mathrm{~ms})$ is much narrower than our previous findings at any age (Personius and Balice-Gordon, 2001). When cross-correlograms are constructed using $2 \mathrm{~ms}$ bins, a 2-4 ms region of zero counts is present (Fig. $4 C)$. This zero count region occurs in single electrode recordings when the activity of both discriminated motor units are superimposed, preventing the Spike2 software from identifying individual spike waveforms at these narrow time differences. Thus, it is possible that our single electrode recording methods missed a large number of potential coincidental spikes within this 2-4 ms window.

The median index $k^{\prime}-1$ value remained significantly greater in MK801-injected mice than saline- or PCPA-injected controls ( $p \leq 0.001$, ANOVA on ranks with Dunn's post hoc test). The mean index $k^{\prime}-1$ was $0.05 \pm 0.06,0.04 \pm 0.03$, and $11.8 \pm 2.6$ for saline-, PCPA-, and MK801-injected pups (Fig. $4 D)(n=26$, 23 , and 19 motor unit pairs, respectively). The mean index $k^{\prime}-1$ for MK801-injected pups was well above previously reported values (Personius and Balice-Gordon, 2001). CI values showed similar large increases in P15-P16 MK801-injected mice compared with saline- or PCPA-injected controls. CI values were calculated using bin widths of 10, 20, 50, and $100 \mathrm{~ms}$ and 1 and $10 \mathrm{~s}$ (Fig. 4E). Significant differences were seen between experimental groups at $10,20,50$, and $100 \mathrm{~ms}$ and $1 \mathrm{~s}$ bin widths ( $p \leq 0.001$, ANOVA on ranks with Dunn's post hoc test). CI values calculated using $10 \mathrm{~ms}$ bin widths (short-term correlations) were $89.4 \pm 20.1,1.1 \pm 0.4$, and $27.7 \pm 11.8$ for MK801-, PCPA-, and saline-injected mice, respectively, indicating that discriminated motor unit pairs from MK801-injected mice were $\sim 62$ times more likely to fire within $10 \mathrm{~ms}$ of each other than those recorded from saline controls.
When CI values were calculated using $100 \mathrm{~ms}$ bin widths (broad correlations), the difference between experimental groups remained statistically significant $(28.3 \pm 3.9,1.5 \pm 0.3$, and $4.2 \pm$ 1.5 for MK801, PCPA, and saline groups, respectively). In our hands, PCPA did not alter motor unit firing frequency or pattern. Thus, our finding that PCPA did not affect the time course of synapse elimination is not surprising. The strength of motor unit correlations in MK801-injected animals at both experimental age groups were greater than our previously reported values in CD-1 pups at $\mathrm{P} 1-\mathrm{P} 2$ when gap junctional coupling is the most robust, suggesting that other cellular mechanisms in addition to gap junctional coupling may control correlation of motor neuron activity during postnatal development.

\section{$\mathrm{Cx} 40, \mathrm{Cx} 43$, and $\mathrm{Cx} 37 \mathrm{mRNA}$ copy numbers are increased after MK801 treatment in P14 mice}

In situ hybridization experiments have shown that $\mathrm{Cx} 36, \mathrm{Cx} 37$, $\mathrm{Cx} 40, \mathrm{Cx} 43$, and $\mathrm{Cx} 45$ are expressed throughout the spinal cord gray matter at birth. Expression gradually becomes more restricted to motor neurons over the first 2 weeks of postnatal development (Chang et al., 1999). During this same timeframe, the percentage of motor neurons expressing $\mathrm{Cx} 40$ and $\mathrm{Cx} 45$ mRNA is reduced by $\sim 80$ and $40 \%$ from the percentages seen at P1, respectively (Chang et al., 1999). To quantify whether connexin expression in the spinal cord was altered by MK 801 treatment, QPCR was used to determine mRNA copy number for Cx45, Cx40, Cx43, and Cx37 (Fig. 5). The lumbar regions of spinal cords were isolated from P14 saline- or MK801-injected pups $(n=6)$. Reverse transcription (RT)-PCR amplification of $\mathrm{Cx} 45, \mathrm{Cx} 40, \mathrm{Cx} 43$, and $\mathrm{Cx} 37$ resulted in the detection of single bands of the appropriate molecular weight. Cx40, Cx43, and Cx37 mRNA expression was significantly increased after MK801 treatment compared with saline controls (Cx40, $10 \pm 5.9$, $100.0 \pm 25.1 ; \mathrm{Cx} 43,5.7 \pm 4.4,947.8 \pm 435.1 ; \mathrm{Cx} 37,46.8 \pm 25.8$, $729.3 \pm 199.0$ mRNA copy number/ $\mu \mathrm{g}$ RNA, saline and MK801 groups respectively). Mann-Whitney rank sum test $p$ values were $p=0.004,0.002$, and 0.004 for $\mathrm{Cx} 40, \mathrm{Cx} 43$, and $\mathrm{Cx} 37$, respectively. Cx45 mRNA expression was also increased in the MK801injected group, but the increase was nonsignificant $(60.3 \pm 33.2$, $136 \pm 32.7 ; p=0.134$, Student's $t$ test).

\section{Motor neuron cell body size is reduced after NMDA receptor blockade}

To investigate whether MK801 treatment alters motor neuron morphology, we immunolabeled frozen spinal cord sections with primary antibodies for ChAT and measured soma CSA in 113 and 155 motor neurons across the lumbar enlargement of MK801- and saline-injected mice, respectively ( $n=6$ mice). Only motor neurons with a visible nucleus were evaluated. ChAT-labeled motor neurons in MK801-injected mice were significantly smaller than in saline-injected mice (Fig. 6A,B). Soma CSA was reduced to $550 \pm 17 \mu \mathrm{m}^{2}$ in MK801-injected mice compared with $758 \pm 19 \mu \mathrm{m}^{2}$ saline control mice (Fig. 6C) ( $p \leq$ 0.001, Mann-Whitney rank sum test). Thus, MK801 treatment appears to not only maintain connexin mRNA levels but may slow other aspects of motor neuron development.

\section{Discussion}

We have shown recently that the loss of a single connexin $(\mathrm{Cx} 40)$ results in reduced gap junctional coupling, reduced correlated motor neuron activity, and precocious synapse elimination at the neuromuscular junction (Personius et al., 2007). Here, we tested whether MK801 injection, shown previously to maintain gap 
junctional coupling among rodent motor neurons, would result in sustained temporally correlated motor unit activity and delay postnatal synaptic competition. MK801 injection was found to maintain correlated motor unit activity throughout the second postnatal week and to delay the time course of synapse elimination by $\sim 4$ d. Because synapse elimination has been shown to occur slowly in the absence of activity (Costanzo et al., 2000), it is possible that MK801 treatment enhances an unknown factor that maintains polyneuronal innervation. However, based on work from multiple laboratories demonstrating the role of activity in synapse elimination (Balice-Gordon and Lichtman, 1994; Busetto et al., 2000, 2003; Buffelli et al., 2002, 2003; Personius and Balice-Gordon, 2002; Personius et al., 2007), we suggest that MK801 injection delays synaptic competition by modulating motor neuron activity patterns through delaying motor neuron growth and the developmental restriction of connexin mRNA expression, preserving correlated motor neuron activity via both gap junctions and synaptic mechanisms.

\section{NMDA receptor blockade slows, but} does not block, synaptic competition MK801 injection slowed synapse elimination in the soleus and EDL muscles by $\sim 4$ $\mathrm{d}$ at both P8-P9 and P14-P15 compared with PCPA- and saline-injected groups or previous reports (Balice-Gordon and Lichtman, 1993; Personius and BaliceGordon, 2001). Synapse elimination could be delayed by either an increase in motor neuron number or a change in neural activity. It is unlikely that synapse elimination was slowed by an increase in motor neuron number innervating the soleus or EDL muscle, because MK801 injections began on P2, well past the developmental time period of motor neuron program cell death (Pittman and Oppenheim, 1978; Oppenheim et al., 2003). Similarly, it is unlikely that increased motor neuron axonal branching influenced synapse elimination, because enhanced developmental branching appears to occur mainly during prenatal development (Nguyen et al., 1998; Oppenheim et al., 2003; Hanson and Landmesser, 2004; Myers et al., 2005). Thus, neural activity is the most likely mechanism by which synapse elimination is delayed by MK801 injection.

\section{NMDA receptor blockade increases the strength of} temporally correlated motor unit activity beyond that normally seen during early postnatal development

The outcome of synaptic competition can clearly be modulated by the amount of neural activity between competing inputs (Buffelli et al., 2003). If MK801 injection resulted in reduced motor unit activity, then delayed synapse elimination would be expected. However, both the firing frequency of motor units and number of motor unit spikes per recording period were not
PCPA injection

MK801 injection

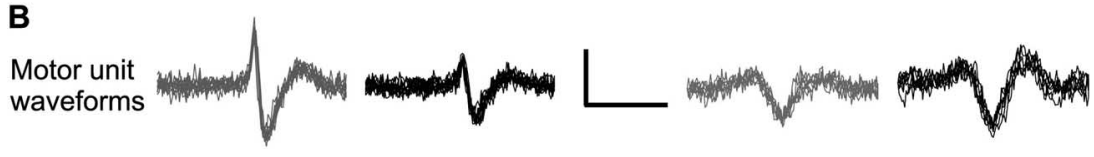

C

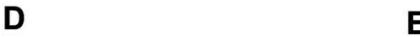

E
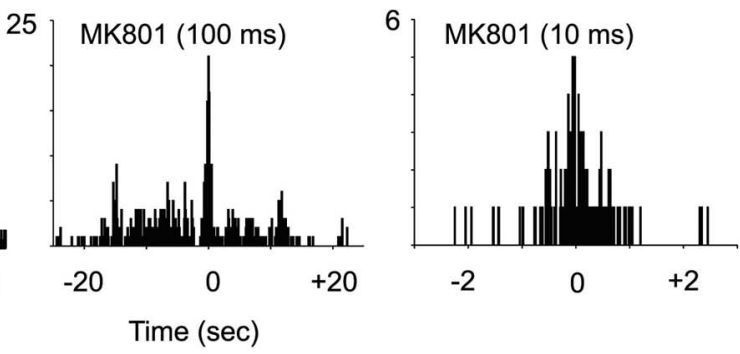

(60)

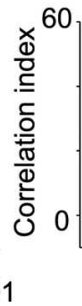

$20 \mathrm{~ms}$

$\mathbf{F}$

$100 \mathrm{~ms}$

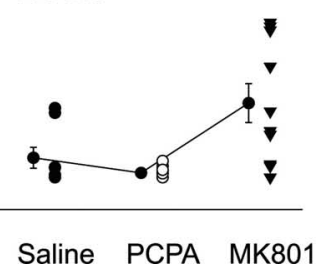

Saline PCPA MK801 Saline PCPA MK801

Figure 3. Temporally correlated motor unit activity is increased in MK801-injected compared with saline- or PCPA-injected lex $k^{\prime}-1(D)$ and by the correlation index over 20 ms $(\boldsymbol{E})$ and $100 \mathrm{~ms}(\boldsymbol{F})$ intervals. Values for each motor unit par are shown (black circles, saline; white circles, PCPA·black triangles, MK801). The connected circles (black) represent the mean + SEM index values for the saline, PCPA, and MK801 experimental groups. The index $k^{\prime}-1$ was significantly increased in MK801injected pups ( $p=0.001$, ANOVA on ranks with Dunn's post hoc test). A similar increase was also seen in the correlation index over 20 ms bins ( $p=0.014$ ) and 100 ms bins ( $p=0.005$, ANOVA on ranks with Dunn's post hoc test; $n=8-11$ motor unit pairs).

slowed by MK801 treatment. Thus, any change in the time course of synapse elimination after MK801 injections is most likely related to the pattern of motor unit activity. We used two methods to quantify the strength of temporally correlated motor unit activity: index $k^{\prime}-1$ and CI. Index $k^{\prime}-1$ and CI values from P7-P8 control pups were both comparable with those reported previously in similarly aged mice (Personius and Balice-Gordon, 2001; Buffelli et al., 2002). MK801-injected pups, however, had index $k^{\prime}-1$ and CI values that were 10-16 times the values reported in P0-P2 pups (Personius and Balice-Gordon, 2001).

P14-P15 control pups had mean index $k^{\prime}-1$ values close to zero, similar to that reported at this age in mice (Personius and Balice-Gordon, 2001) and rats (Buffelli et al., 2002). Index $k^{\prime}-1$ and CI values in MK801-treated mice were 30 and 12 times the values reported in young rodents, respectively (Personius and Balice-Gordon, 2001; Buffelli et al., 2002). These very high correlation values do not appear to be biologically impossible, because CI values determined from $100 \mathrm{~ms}$ bins average $\sim 60-70$ for closely spaced retinal ganglion cell during the first postnatal week in ferrets and mice (Wong et al., 1993; Demas et al., 2003; 
A PCPA injection

MK801 injection

Raw
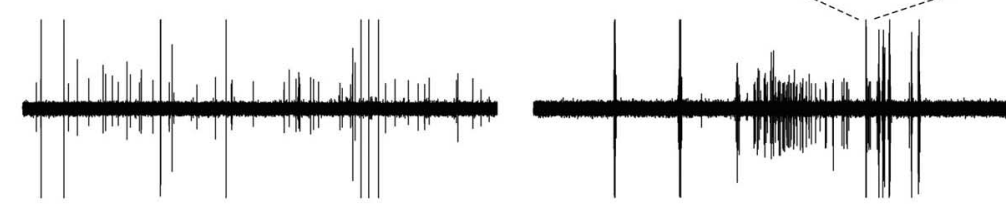

B

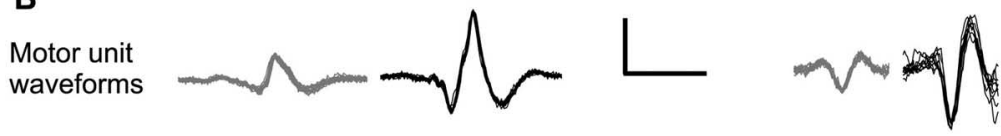

C
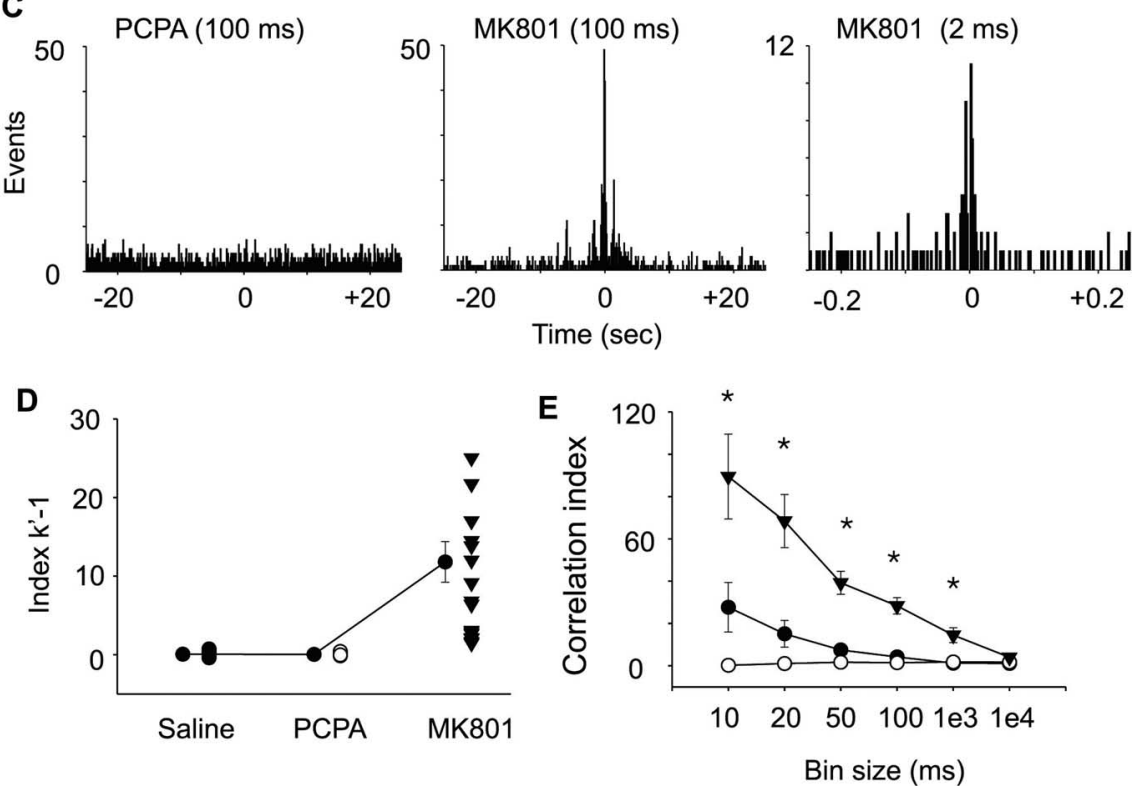

Figure 4. Temporally correlated motor unit activity is present at P15-P16 in MK801-injected mice but not in PCPA- or salineinjected controls. $\boldsymbol{A}, \boldsymbol{B}$, Raw EMG records $(\boldsymbol{A})$ and waveform overlays of two discriminated motor units $(\boldsymbol{B})$ (calibration bars: $0.2 \mathrm{mV}$, $10 \mathrm{~s}$; and $0.3 \mathrm{mV}, 3 \mathrm{~ms}$, respectively). Motor behavior remained more ballistic in MK801-injected animals compared with salineinjected control. Note burst of activity within the expanded plot. C, Strong temporal correlations were seen in motor unit recordings from MK801-injected mice, but no correlated activity was found in PCPA-injected controls. The left cross-correlogram is from a PCPA control mouse and shows no correlation. The middle (100 ms bins) and right ( $2 \mathrm{~ms}$ bins) cross-correlograms are from the same MK801-injected animal and show tight correlations over a period of $23 \mathrm{~ms}$. $\boldsymbol{D}, \boldsymbol{E}$, The strength of temporal correlation for each motor unit pair was determined by the index $k^{\prime}-1(\boldsymbol{D})$ and by the correlation index $(\boldsymbol{E})$ over increasing bin widths. Values for each motor unit pair are shown (black circles, saline; white circles, PCPA; black triangles, MK801). The connected circles (black) represent the mean \pm SEM index values for the saline, $P C P A$, and MK801 experimental groups. The index $k^{\prime}-1$ was significantly increased in the MK801 group ( $p=0.001$, ANOVA on ranks with Dunn's post hoc test). The correlation index was greater at smaller bin widths in MK801-injected than saline- or PCPA-injected mice at 10, 20, 50, 100, or 1000 ms bin widths ( $p=0.001$, ANOVA on ranks with Dunn's post hoc test; $n=19-26$ motor unit pairs; black circles, saline; white circles, PCPA; black triangles, MK801).

Eglen et al., 2003). Because the strength of temporal correlations between motor units is increased in MK801-injected animals beyond that reported previously at any postnatal age, it suggests that other cellular mechanisms in conjunction with gap junctional coupling may modulate motor unit correlation during postnatal development. Thus, enhanced intrinsic motor neuron excitability, increased excitatory chemical synaptic connections, together with maintained gap junctional coupling among motor neurons and/or interneurons may result in the supernormal correlative motor activity seen after MK801 treatment (Hanson and Landmesser, 2004; Hansen et al., 2005).
Relevant temporal window of correlated activity during postnatal development The temporal window or timescale of correlated activity necessary for synaptic plasticity to occur during development of the neuromuscular junction is unclear. During visual system development, temporal correlations occur across several seconds (Wong et al., 1993, 1998), whereas in retinotectal neurons in vivo (Zhang et al., 1998) and dissociated hippocampal neurons in vitro (Bi and Poo, 1998, 2001), the temporal window necessary to modulate synaptic strength is $\sim 20 \mathrm{~ms}$. When two motor neurons are electrically coupled, an action potential in one cell will result in a short-latency depolarization (SLD) in the second cell. Membrane depolarizations caused by an SLD peak within 2-3 $\mathrm{ms}$ and decay by $\sim 50 \mathrm{~ms}$ after the ventral root stimulus (Mentis et al., 2002; Personius et al., 2007). Thus, if SLDs were the only mechanism responsible for the correlated firing of motor neurons, a peak in the cross-correlogram would occur within a few milliseconds of the firing of one of the coupled cells and persist no longer than $\sim 50 \mathrm{~ms}$. We found that the peak in the cross-correlogram was 1-2 s in MK801-injected pups at P7-P8 and 20-50 ms at P15-P16. Because, CI values of motor unit correlation were increased at both $20 \mathrm{~ms}$ (short-term) and $100 \mathrm{~ms}$ (broad) bin widths, multiple mechanisms appear to influence correlated motor unit activity during development.

The broad correlations we observed in the firing of motor units at P7-P8 were centered at 0 time, suggesting the presence of common synaptic inputs onto the two motor unit pairs. Slow ventral root potentials synchronized across several segments of the spinal cord are seen in spontaneous motor neuron recordings in isolated spinal cords of the neonatal mouse (Whelan et al., 2000). This synchronized activity is abolished by the NMDA receptor antagonist AP-5 (Li and Burke, 2001), suggesting that it is synaptically mediated. Tresch and Kiehn (2002) showed that motor neuron pairs in the isolated neonatal rat cord exhibited correlated activity during drug-induced locomotor-like activity. Because correlated motor neuron activity persisted in the presence of carbenoxolone, a gap junction blocker, a synaptic mechanism for correlated motor neuron activity is again suggested. Common synaptic inputs could result from spinal interneurons or from synaptically coupled motor neurons (Mentis et al., 2005; Nishimaru et al., 2005). It is also possible that the chloride equilibrium potential may be above rest in some motor neurons or in spinal interneurons, thereby resulting in depolarizing GABAergic and glycinergic synaptic potentials (Hanson 


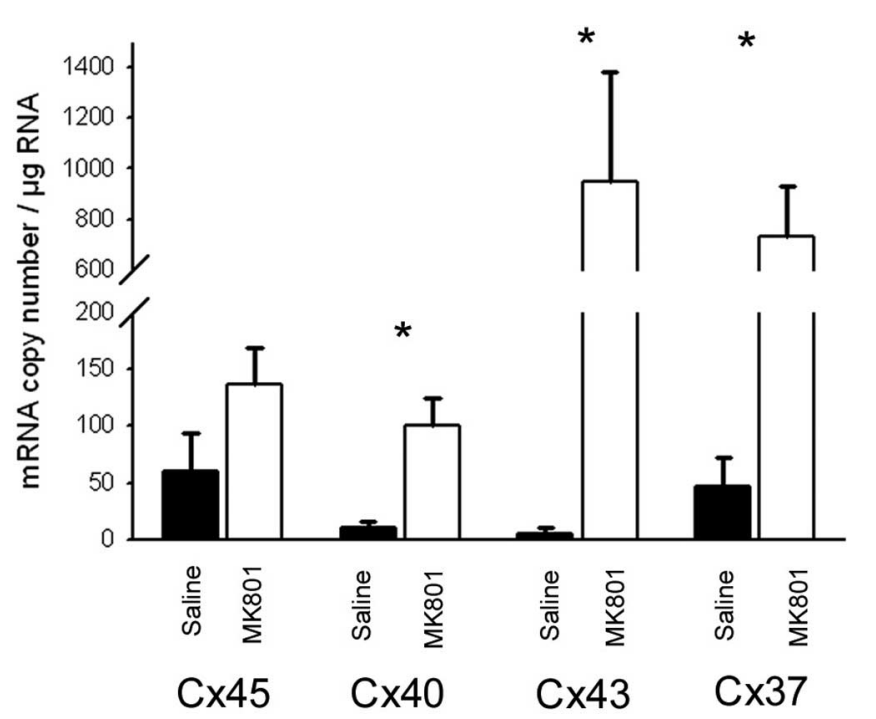

Figure 5. mRNA copy number of $\mathrm{C} x 40, \mathrm{C} \times 43$, and $\mathrm{C} \times 37$ in spinal cord were increased after MK801 treatment in P14 mice. Single bands of the appropriate molecular weight were detected after RT-PCR amplification of $C x 45, C x 40, C x 43$, and $C x 37$. QPCR was used to determine whether connexin mRNA copy number was altered by MK801 treatment. $C \times 40, C \times 43$, and $C \times 37$ mRNA copy number were significantly increased by MK801 injection in P14 pups compared with saline controls ( $p=0.004,0.002$, and 0.004 , respectively, Mann-Whitney rank sum test). No change in Cx45 expression was observed ( $p=0.134$, Student's $t$ test). Copy number was determined based on absolute quantification using an external calibration curve constructed from measurements of cloned PCR products for each connexin. mRNA copy number is expressed per microgram sample mRNA.

and Landmesser, 2004). In addition, it seems likely that electrical coupling between interneurons may also be reduced during normal development. Consistent with this idea, it has been shown recently that locomotor-related spinal interneurons are electrically interconnected. Such connections appear to contribute to the common synaptic input that coupled pairs of these interneurons receive and to their correlated firing during drug-induced locomotor-like activity (Hinckley and Ziskind-Conhaim, 2006).

Why the peak in the cross-correlogram would narrow from a period of seconds to milliseconds in MK801-injected pups from $\mathrm{P} 7$ to $\mathrm{P} 15$ is an interesting question. In adult animals and humans, short-term correlations $(\leq 50 \mathrm{~ms})$ between motor units are thought to be driven by presynaptic inputs from descending cortical neurons (Sears and Stagg, 1976; Nordstrom et al., 1992). Mature corticospinal presynaptic inputs appear to be the most important synaptic input for producing short-term synchronization (Brouwer and Ashby, 1992; Palmer and Ashby, 1992). Because the earliest corticospinal projections in rodents arrive at the end of the first postnatal week (Vinay et al., 2000), the synaptic connections that produce correlated activity during early postnatal development must be restricted to the spinal cord and be independent of cortical input. Thus, very strong short-term correlation $(\leq 50$ ms) may only be seen in P14-P15 mice when gap junctional coupling among interneurons and motor neurons is maintained and when corticospinal presynaptic inputs are established. However, in P7-P8 MK801-injected mice, immature synaptic connections result in broad correlations. This suggests that synaptic inputs to motor neurons result in broad correlation during early postnatal development and that short-term correlations are only seen as spinal synaptic connections mature. Together, these results suggest that motor

\section{Saline-control}
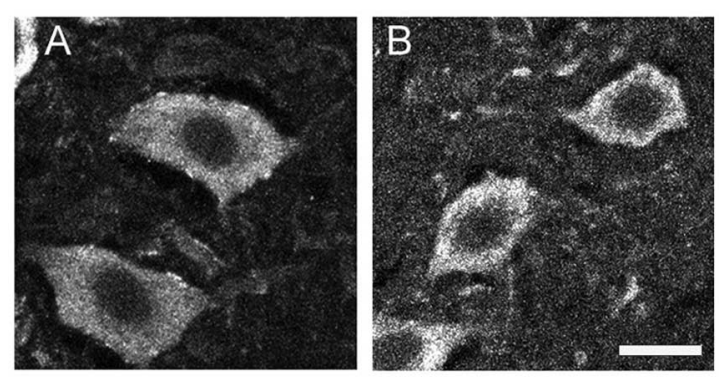

C

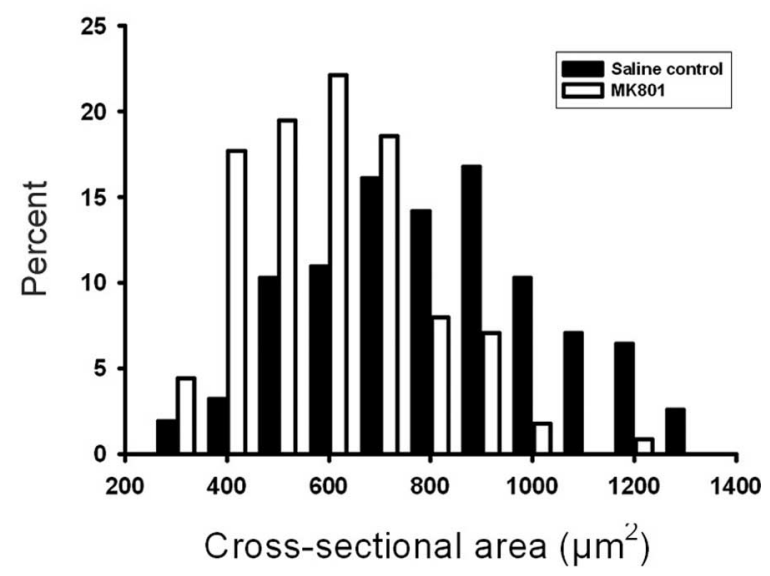

Figure 6. Motor neuron cell body size is reduced in MK801 compared with salineinjected mice. $\boldsymbol{A}, \boldsymbol{B}$, Motor neurons from P14 mice were immunolabeled for ChAT. Motor neurons were identified by their large soma size and ventral horn motor column location. Only motor neurons with a visible nucleus were included in CSA measurement. Scale bar, $20 \mu \mathrm{m}$. Both the location and number of motor neurons in MK801-injected mice appeared normal, but their cell body size was frequently smaller than saline-injected controls. C, A frequency histogram of motor neuron soma CSA showing the reduction in CSA of MK801 compared with saline-injected mice ( $p \leq 0.001$, Mann-Whitney rank sum test; measurements were made from 113 and 155 motor neurons within the lumbar enlargement from MK801 and saline-injected mice; $n=6$ mice).

unit correlation during postnatal development is modulated by both gap junctional coupling between neurons and by local synaptic inputs to motor neurons, resulting in both short $(\leq 50 \mathrm{~ms})$ and broad (100 ms to $2 \mathrm{~s})$ correlated activity ( $\mathrm{Hu}$ and Bloomfield, 2003; Hansen et al., 2005).

\section{NMDA receptor blockade maintains connexin mRNA} expression in the spinal cord

Restriction of connexin expression in the spinal cord is postulated to underlie the reduction of motor neuron correlated activity during development. Our finding that $\mathrm{Cx} 40, \mathrm{Cx} 43$, and $\mathrm{Cx} 37$ mRNA copy number were increased by MK801 treatment generally agree with this possibility. The reduction in motor neuron size in MK801-treated mice also suggests that NMDA blockade may slow other aspects of neuron maturation.

Building on Mentis et al. (2002) and the results presented here, the blockade of NMDA receptor input by MK801 injection appears to maintain gap junctional coupling and delay the developmental restriction of connexin mRNA expression within the spinal cord. Maintained gap junction coupling among motor neurons is likely attributable to modulation of constitutively expressed gap junction proteins within motor neurons. Enhanced temporally correlated motor unit activity 
may emerge from maintained gap junctional coupling among interneurons and motor neurons and altered synaptic input to motor neurons. Finally, the enhanced correlated motor unit activity delays synaptic competition at the neuromuscular junction. Thus, the onset of locomotion, associated with increased glutamatergic synaptic activity within the spinal cord (Vinay et al., 2000), may ultimately modulate synapse elimination.

\section{References}

Balice-Gordon RJ, Lichtman JW (1993) In vivo observations of pre- and postsynaptic changes during the transition from multiple to single innervation at developing neuromuscular junctions. J Neurosci 13:834-855.

Balice-Gordon RJ, Lichtman JW (1994) Long-term synapse loss induced by focal blockade of postsynaptic receptors. Nature 372:519-524.

Banks GB, Kanjhan R, Wiese S, Kneussel M, Wong LM, O’Sullivan G, Sendtner M, Bellingham MC, Betz H, Noakes PG (2005) Glycinergic and GABAergic synaptic activity differentially regulate motoneuron survival and skeletal muscle innervation. J Neurosci 25:1249-1259.

Bi G, Poo M (2001) Synaptic modification by correlated activity: Hebb's postulate revisited. Annu Rev Neurosci 24:139-166.

Bi GQ, Poo MM (1998) Synaptic modifications in cultured hippocampal neurons: dependence on spike timing, synaptic strength, and postsynaptic cell type. J Neurosci 18:10464-10472.

Brouwer B, Ashby P (1992) Corticospinal projections to lower limb motoneurons in man. Exp Brain Res 89:649-654.

Buffelli M, Busetto G, Cangiano L, Cangiano A (2002) Perinatal switch from synchronous to asynchronous activity of motoneurons: link with synapse elimination. Proc Natl Acad Sci U S A 99:13200-13205.

Buffelli M, Burgess RW, Feng G, Lobe CG, Lichtman JW, Sanes JR (2003) Genetic evidence that relative synaptic efficacy biases the outcome of synaptic competition. Nature 424:430-434.

Busetto G, Buffelli M, Tognana E, Bellico F, Cangiano A (2000) Hebbian mechanisms revealed by electrical stimulation at developing rat neuromuscular junctions. J Neurosci 20:685-695.

Busetto G, Buffelli M, Cangiano L, Cangiano A (2003) Effects of evoked and spontaneous motoneuronal firing on synapse competition and elimination in skeletal muscle. J Neurocytol 32:795-802.

Callaway EM, Soha JM, Van Essen DC (1987) Competition favouring inactive over active motor neurons during synapse elimination. Nature 328:422-426.

Chang Q, Gonzalez M, Pinter MJ, Balice-Gordon RJ (1999) Gap junctional coupling and patterns of connexin expression among neonatal rat lumbar spinal motor neurons. J Neurosci 19:10813-10828.

Costanzo EM, Barry JA, Ribchester RR (2000) Competition at silent synapses in reinnervated skeletal muscle. Nat Neurosci 3:694-700.

Demas J, Eglen SJ, Wong RO (2003) Developmental loss of synchronous spontaneous activity in the mouse retina is independent of visual experience. J Neurosci 23:2851-2860.

Eglen SJ, Demas J, Wong RO (2003) Mapping by waves. Patterned spontaneous activity regulates retinotopic map refinement. Neuron 40:1053-1055.

Farkas S, Ono H (1995) Participation of NMDA and non-NMDA excitatory amino acid receptors in the mediation of spinal reflex potentials in rats: an in vivo study. Br J Pharmacol 114:1193-1205.

Fenaux F, Corio M, Palisses R, Viala D (1991) Effects of an NMDA-receptor antagonist, MK-801, on central locomotor programming in the rabbit. Exp Brain Res 86:393-401.

Fulton BP, Miledi R, Takahashi T (1980) Electrical synapses between motoneurons in the spinal cord of the newborn rat. Proc R Soc Lond B Biol Sci 208:115-120.

Gonzalez M, Ruggiero FP, Chang Q, Shi YJ, Rich MM, Kraner S, BaliceGordon RJ (1999) Disruption of Trkb-mediated signaling induces disassembly of postsynaptic receptor clusters at neuromuscular junctions. Neuron 24:567-583.

Gosselin LE, Williams JE, Personius K, Farkas GA (2007) A comparison of factors associated with collagen metabolism in different skeletal muscles from dystrophic $(\mathrm{mdx})$ mice: impact of pirfenidone. Muscle Nerve 35:208-216.

Hansen KA, Torborg CL, Elstrott J, Feller MB (2005) Expression and func- tion of the neuronal gap junction protein connexin 36 in developing mammalian retina. J Comp Neurol 493:309-320.

Hanson MG, Landmesser LT (2004) Normal patterns of spontaneous activity are required for correct motor axon guidance and the expression of specific guidance molecules. Neuron 43:687-701.

Hinckley CA, Ziskind-Conhaim L (2006) Electrical coupling between locomotor-related excitatory interneurons in the mammalian spinal cord. J Neurosci 26:8477-8483.

Hu EH, Bloomfield SA (2003) Gap junctional coupling underlies the shortlatency spike synchrony of retinal $\alpha$ ganglion cells. J Neurosci 23:6768-6777.

Lauder JM, Wilkie MB, Wu C, Singh S (2000) Expression of 5-HT(2A), 5-HT(2B) and 5-HT(2C) receptors in the mouse embryo. Int J Dev Neurosci 18:653-662.

Li Y, Burke RE (2001) Short-term synaptic depression in the neonatal mouse spinal cord: effects of calcium and temperature. J Neurophysiol 85:2047-2062.

Lichtman JW, Colman H (2000) Synapse elimination and indelible memory. Neuron 25:269-278.

Meister M, Wong RO, Baylor DA, Shatz CJ (1991) Synchronous bursts of action potentials in ganglion cells of the developing mammalian retina. Science 252:939-943.

Mentis GZ, Díaz E, Moran LB, Navarrete R (2002) Increased incidence of gap junctional coupling between spinal motoneurones following transient blockade of NMDA receptors in neonatal rats. J Physiol 544:757-764.

Mentis GZ, Alvarez FJ, Bonnot A, Richards DS, Gonzalez-Forero D, Zerda R, O'Donovan MJ (2005) Noncholinergic excitatory actions of motoneurons in the neonatal mammalian spinal cord. Proc Natl Acad Sci U S A 102:7344-7349.

Myers CP, Lewcock JW, Hanson MG, Gosgnach S, Aimone JB, Gage FH, Lee KF, Landmesser LT, Pfaff SL (2005) Cholinergic input is required during embryonic development to mediate proper assembly of spinal locomotor circuits. Neuron 46:37-49.

Nguyen QT, Parsadanian AS, Snider WD, Lichtman JW (1998) Hyperinnervation of neuromuscular junctions caused by GDNF overexpression in muscle. Science 279:1725-1729.

Nishimaru H, Restrepo CE, Ryge J, Yanagawa Y, Kiehn O (2005) Mammalian motor neurons corelease glutamate and acetylcholine at central synapses. Proc Natl Acad Sci U S A 102:5245-5249.

Nordstrom MA, Fuglevand AJ, Enoka RM (1992) Estimating the strength of common input to human motoneurons from the cross-correlogram. J Physiol 453:547-574.

Oppenheim RW, Calderó J, Cuitat D, Esquerda J, Ayala V, Prevette D, Wang S (2003) Rescue of developing spinal motoneurons from programmed cell death by the GABA(A) agonist muscimol acts by blockade of neuromuscular activity and increased intramuscular nerve branching. Mol Cell Neurosci 22:331-343.

Palmer E, Ashby P (1992) Corticospinal projections to upper limb motoneurones in humans. J Physiol 448:397-412.

Personius KE, Balice-Gordon RJ (2001) Loss of correlated motor neuron activity during synaptic competition at developing neuromuscular synapses. Neuron 31:395-408.

Personius KE, Balice-Gordon RJ (2002) Activity-dependent synaptic plasticity: insights from neuromuscular junctions. Neuroscientist 8:414-422.

Personius KE, Chang Q, Mentis GZ, O’Donovan MJ, Balice-Gordon RJ (2007) Reduced gap junctional coupling leads to uncorrelated motor neuron firing and precocious neuromuscular synapse elimination. Proc Natl Acad Sci U S A 104:11808-11813.

Pflieger JF, Clarac F, Vinay L (2002) Postural modifications and neuronal excitability changes induced by a short-term serotonin depletion during neonatal development in the rat. J Neurosci 22:5108-5117.

Pittman RH, Oppenheim RW (1978) Neuromuscular blockade increases motoneurone survival during normal cell death in the chick embryo. Nature 271:364-366.

Ribchester RR (1993) Co-existence and elimination of convergent motor nerve terminals in reinnervated and paralysed adult rat skeletal muscle. J Physiol 466:421-441.

Ridge RM, Betz WJ (1984) The effect of selective, chronic stimulation on motor unit size in developing rat muscle. J Neurosci 4:2614-2620.

Sanes JR, Lichtman JW (2001) Induction, assembly, maturation and maintenance of a postsynaptic apparatus. Nat Rev Neurosci 2:791-805. 
Sears TA, Stagg D (1976) Short-term synchronization of intercostal motoneurone activity. J Physiol 263:357-381.

Thompson W (1983) Synapse elimination in neonatal rat muscle is sensitive to pattern of muscle use. Nature 302:614-616.

Torborg CL, Hansen KA, Feller MB (2005) High frequency, synchronized bursting drives eye-specific segregation of retinogeniculate projections. Nat Neurosci 8:72-78.

Tresch MC, Kiehn O (2000) Motor coordination without action potentials in the mammalian spinal cord. Nat Neurosci 3:593-599.

Tresch MC, Kiehn O (2002) Synchronization of motor neurons during locomotion in the neonatal rat: predictors and mechanisms. J Neurosci 22:9997-10008.

Vinay L, Brocard F, Pflieger JF, Simeoni-Alias J, Clarac F (2000) Perinatal development of lumbar motoneurons and their inputs in the rat. Brain Res Bull 53:635-647.
Walton KD, Navarrete R (1991) Postnatal changes in motoneurone electrotonic coupling studied in the in vitro rat lumbar spinal cord. J Physiol 433:283-305.

Whelan P, Bonnot A, O'Donovan MJ (2000) Properties of rhythmic activity generated by the isolated spinal cord of the neonatal mouse. J Neurophysiol 84:2821-2833.

Wong RO, Meister M, Shatz CJ (1993) Transient period of correlated bursting activity during development of the mammalian retina. Neuron 11:923-938.

Wong WT, Sanes JR, Wong RO (1998) Developmentally regulated spontaneous activity in the embryonic chick retina. J Neurosci 18:8839-8852.

Zhang LI, Tao HW, Holt CE, Harris WA, Poo M (1998) A critical window for cooperation and competition among developing retinotectal synapses. Nature 395:37-44. 